\title{
A Mitigating Technique for the Treatment of Small Volumes Drinking Water from Radon Gas
}

\author{
Saddig D. Jastaniah, Bassam Z. Shakhreet, Hanan Y. Abbas \\ Department of Diagnostic Radiology, Faculty of Applied Medical Sciences, King Abdulaziz University, Jeddah, KSA \\ Email: sjastaniah@kau.edu.sa
}

Received October 23, 2013; revised November 25, 2013; accepted December 2, 2013

Copyright (C) 2014 Saddig D. Jastaniah et al. This is an open access article distributed under the Creative Commons Attribution License, which permits unrestricted use, distribution, and reproduction in any medium, provided the original work is properly cited. In accordance of the Creative Commons Attribution License all Copyrights (C) 2014 are reserved for SCIRP and the owner of the intellectual property Saddig D. Jastaniah et al. All Copyright (C) 2014 are guarded by law and by SCIRP as a guardian.

\section{ABSTRACT}

We made an evaluation of a suitable mitigation technique for the treatment of drinking water that was artificially enriched with $\mathrm{Rn}-222$ in laboratory by placing a radium rich granite stone (pitchblende) in a closed container filled with tap water for several days in order to allow Rn-222 concentration to approach its highest possible level. Experiments were designed to investigate the effectiveness of removal of Rn-222 by diffused bubble aeration method at room temperature. The results showed that this method becomes more efficient at higher airto-water ratios. Better aeration depends on the length of travel of bubbles through the water depth. This method is practical and has low capital cost. The removal of $\mathbf{R n - 2 2 2}$ from artificially enriched water can be practically achieved by diffused bubble aeration method to greater than $98 \%$.

\section{KEYWORDS}

\section{Radon; Mitigation; Drinking Water}

\section{Introduction}

Radon (Rn-222) is continuously being produced from Radium (Ra-226) in rocks and soil. Acidic rocks such as granite usually contain large quantities of Ra-226; therefore higher rates of Rn-222 may be released from it. The released Rn-222 from rocks and soil is likely to be dissolved in ground-waters, which will eventually emanate into the atmosphere with low concentration in air as reported [1-3]. Rn-222 concentration may vary due to several factors, such as its geological environment [4] and water consumption rate [5].

In 1984, The National Council of Radiation Protection (NCRP) [6] published a report in which they described the sources of Rn-222 in the global atmosphere, and stated that the major source of Rn-222 is the normal emanation from Ra-226 in the earth's crust.

The treatment of $\mathrm{Rn}-222$ rich water by suitable mitigating techniques is necessary for cases of well water containing elevated level of Rn-222; since there is an increasing evidence correlating ingestion of $\mathrm{Rn}-222$ rich water and the potential for induction of internal cancers
$[7,8]$

The Rn-222 removal from water by different treatment processes, such as Granular Activated Carbon (GAC) adsorption, and various forms of aeration was described [9].

Two types of treatment processes have been widely used to remove Rn-222 from water supplies by Aeration technique: 1) diffused bubble aeration system; 2) packed lower aeration system.

Many designs have been developed in order to achieve an effective diffused bubble aeration system [9-11]. All these designs were based on diffusing air bubbles from the bottom of a tank, displacing Rn-222 gas from water.

The aeration technology for Rn-222 removal was evaluated [10]. Spray jet aeration, packed tower aeration, and multistage bubble aeration were evaluated. The spray jet has a special design consisting of a nozzle that will force the water through precisely engineered orifices, creating a vacuum that draws air in through the rear of the unit. The study concluded that spray jet was very effective, and its efficiency depends on the packing height.

Individuals may get exposed to Rn-222 through inhalation or ingestion, or both. The dose measured for people 
drinking water rich with $\mathrm{Rn}-222$ was investigated by many people [12-14].

Development of a standard for maximum Rn-222 concentration in water requires optimization between public health and cost. In the United states EPA proposed a rule regulating radionuclide concentrations in drinking water [15]. An average of $10,000 \mathrm{pCi} / \mathrm{L} \mathrm{Rn}-222$ in water contributes about $1 \mathrm{pCi} / \mathrm{L} \mathrm{Rn}-222$ to indoor air.

Under the basis of EPA's proposed rule for Rn-222 standard in drinking water [16] have estimated the cost of compliance with the drinking water level of $300 \mathrm{pCi} / \mathrm{L}$ for Rn-222.

The removal efficiency of moderate levels of radon from groundwater supplies was evaluated using the diffused bubble aeration technique [17]. An aeration system was designed, constructed and operated for that purpose. The effect of air-to-water ratio and detention time on radon removal was evaluated through 32 runs. The possibility to reduce the radon activity in the influent stream to the US Environmental Protection Agency proposed maximum contaminant level (MCL) was verified through many alternative combined values of both air-to-water ratios and detention times. The results showed that at detention time of 19 minutes and air-to-water ratio of 12 , the average radon removal is about $97 \%$. The stripping constant characterizing this system was calculated and the removal efficiency at extended values of detention time was predicted. The data obtained are site specific, being dependent on container size, type of diffusers, temperature, and influent radon radioactivity.

Rn-222 concentrations in ground and drinking water of nine cities of Chihuahua State, Mexico were reported by (Villalba L. et al. 2005) [18]. Fifty percent of the 114 sampled wells exhibited Rn-222 concentrations exceeding $11 \mathrm{~Bq} / \mathrm{L}$, the maximum contaminant level (MCL) recommended by the USEPA. Furthermore, around $48 \%$ (123 samples) of the tap-water samples taken from 255 dwellings showed radon concentrations over the MCL. There is an apparent correlation between total dissolved solids and radon concentration in ground-water. The high levels of Rn-222 found may be entirely attributed to the nature of aquifer rocks.

The concentration of uranium and radon has been assessed in drinking water samples collected from different areas belonging to the upper Siwaliks of Kala Amb, Nahan and Morni Hills of Haryana and Himachal Pradesh states, India by (Singh et al. 2008) [19]. The water samples are taken from hand pumps, natural sources and wells. Fission track registration technique has been used to estimate the uranium content of water samples. Most of the water samples are found to have uranium concentration below the safe limit of $15 \mu \mathrm{g} / \mathrm{L}$. The radon estimation in these samples has been made using $\alpha$-scintillometry to study its correlation with uranium. The radon concentration in these samples is found to vary from
$(0.87 \pm 0.29)$ to $(32.10 \pm 1.79) \mathrm{Bq} / \mathrm{L}$. The recorded values of radon concentration are within the recommended safe limit of $40 \mathrm{~Bq} / \mathrm{L}$. No direct correlation is found between uranium concentration and radon concentration in water samples belonging to upper Siwaliks. The values of uranium and radon concentration in water are compared with those from the adjoining areas of Punjab.

\section{Treatment of Rn-222 Rich Water by Aeration Method}

The purpose of the following experiments is to evaluate the reliability of a diffused bubble aeration technique on a laboratory scale. In the laboratory, small volumes of water are used and factors related to use of aeration for reducing Rn-222 concentration in water can be investigated under controlled conditions. Factors such as aeration time, bubbling rate, volume of water, surface area of water and its geometry, and effect of the water temperature can be conveniently studied.

\subsection{Materials and Equipment}

The materials that were essential to do all the aeration experiments are:

Rn-222 enriched water, high efficiency mineral oil scintillator, borosilicate scintillation vials of $20 \mathrm{ml}$ capacity with tin foil lined caps, glass cylinders, beakers, syringes and aerators (ball and ring type, usually found in fish accessories store).

The equipment that was used consisted of:

Air pump, air flow meter, timer, voltage stabilizer, liquid scintillation counter-type LSC2 (NE Technology) and scalar rate meter-type SR8 (NE Technology).

\subsection{Procedures and Methods}

\subsubsection{Preparation of Rn-222 Rich Water in Laboratory}

Radon rich water was prepared in the laboratory by placing a radium granite rock (pitchblende) in a glass container filled with tap water. The cap of the container was then secured to insure no leakage of Rn-222 produced from the decay of Ra-226 isotope. After several days the water becomes highly enriched with Rn-222 gas. Measurements show that the level of Rn-222 present in such water, depending upon length of elapsed time, may reach values as high as $100,000 \mathrm{pCi} / \mathrm{L}$ which is high enough concentration for conducting Rn-222 mitigation experiments. Dilutions were made from these high $\mathrm{Rn}-222$ concentrations to the range of $(1000-10,000) \mathrm{pCi} / \mathrm{L} \mathrm{Rn}-222$ water samples.

\subsubsection{Components of the Diffused Bubble Aeration System}

Two diffused bubble aeration systems were involved in 
the aeration experiments, depending on the aerator type. The first diffused bubble aeration system is shown in Figure 1.

The aerator has a ball shape, thus called ball type aerator. The function of the voltage stabilizer is to keep a consistent current passing through the air pump. This is necessary in order to regulate the quantities of air produced by the pump and transferred to the air flow meter.

The scale readings are divided into units from 10 to 100. Calibration was done by the manufacturing company in order to give corresponding readings in ( $\mathrm{ml} / \mathrm{min})$. A glass cylinder (100 ml capacity, $6.5 \mathrm{~cm}^{2}$ surface areas) is shown in Figure too. This glass contains Rn-222 enriched water. At the bottom of the cylinder there is a ball (radius $=1 \mathrm{~cm}$ ) that has a lot of fine holes on its surface. The ball is connected to the air flow meter by a hose. The holes on the ball allow the air to pass through the water forming small bubbles.

The second diffused bubble aeration system is similar to the system described above. The only difference is the aerator type as shown in Figure 2. It is used for larger water volumes. A glass beaker, $500 \mathrm{ml}$ capacity, $52 \mathrm{~cm}^{2}$ surface areas is used. For this, the ball aerator is no longer sufficient to distribute bubbles homogeneously throughout the volume of water, and a ring type aerator, inner radius $=1 \mathrm{~cm}$, outer radius $=3 \mathrm{~cm}$ is used.

\subsubsection{Examine the Effect of Aeration Time on Rn-222 Removal Using Diffused Bubble Aeration System}

Experiments were designed towered studying the effect of aeration time on Rn-222 removal from water using the

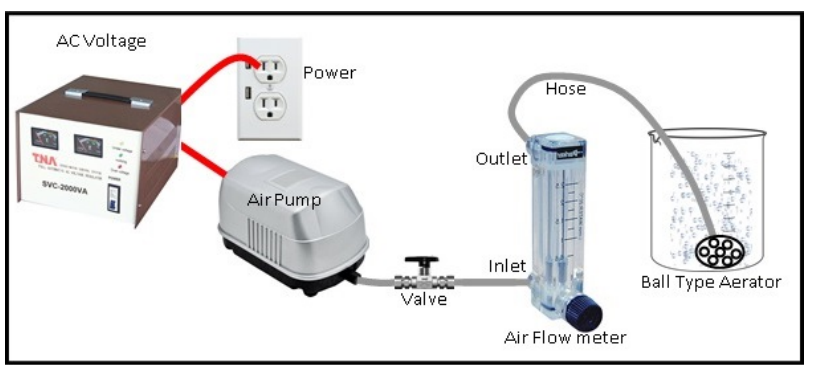

Figure 1. Ball type diffused bubble aeration system.

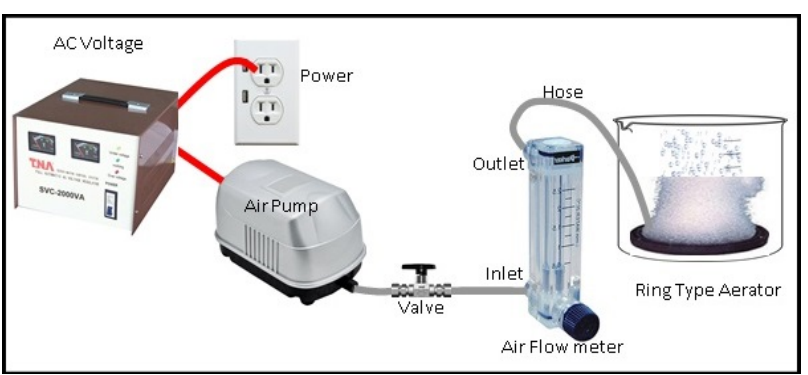

Figure 2. Ring type diffused bubble aeration system. two diffused bubble aeration systems described above. In order to perform these experiments the air flow rate was kept constant at $70 \mathrm{ml} / \mathrm{min}$. Aeration time was allowed to increase while taking a sample every one minute until most of the Rn-222 gas was eliminated from the water. The experiments were repeated twice.

Because the starting Rn-222 concentrations in these experiments were not similar, although they varied from 5000 to $10,000 \mathrm{pCi} / \mathrm{L}$, it was necessary to measure the $\mathrm{Rn}-222$ removal with respect to what is left, i.e. relative radon reminder.

Since it took only few minutes of experimentation for most of the Rn-222 to be eliminated, the natural decay of $\mathrm{Rn}-222$ is neglected. The only cause of Rn-222 loss from water will then be due to aeration, while keeping the other factors i.e. temperature, water volume, surface area, air flow rate, and geometry constant for each experiment.

It is important to account for the natural loss of Rn222 from water during the experiment, which is due to natural escape from the open surface of the water. A control sample was taken from a second similar but nonaerated system each time a sample was taken from the aerated system. This is achieved by preparing a beaker with the same specifications of water volume, surface area etc. as the aeration system beaker, and filling it with similarly Rn-222 enriched water.

\subsubsection{Examine the Effect of Air Flow Rate on Rn-222 Removal Using Diffused Bubble Aeration System}

In order to study the effect of air flow rate on Rn-222 removal using diffused bubble aeration system, a set of experiments similar to those described in last sub-section were adopted, except that the aeration time was kept fixed for each experiment. Here, the air flow rate was allowed to increase and samples were taken whenever air flow rate is changed (by adjusting the flow meter). All the experiments were repeated twice.

\subsubsection{Volume and Surface Area Effect}

Aeration time and air flow rate effects were tested for four volumes (50, 100, 200, and 300) $\mathrm{ml}$. The surface area in the (50 and 100) $\mathrm{ml}$ was $6.5 \mathrm{~cm}^{2}$, while the surface area of the (200 and 300) $\mathrm{ml}$ was $52 \mathrm{~cm}^{2}$. Different surface areas can significantly affect the efficiency of the aeration system. Therefore, it becomes essential to study this effect. In order to do that, the natural loss of Rn-222 on standing from two surface areas (cylinder $=22 \mathrm{~cm}^{2}$, beaker $=82 \mathrm{~cm}^{2}$ ) was determined. The volume of the Rn222 rich water used for both the cylinder and the beaker was $500 \mathrm{ml}$. Samples were taken for measurements as time passed. The experiment was repeated twice, at room temperature. 


\section{Results and Discussion}

\subsection{The Optimum Aeration Time for Rn-222 Removal from Water Using Diffused Bubble Aeration System}

The results of two repeated sets of experiments determining the effect of aeration time on Rn-222 removal from water for four volumes $\left(50,100 \mathrm{ml}\right.$ with $6.5 \mathrm{~cm}^{2}$ surface area and 200, $300 \mathrm{ml}$ with $52 \mathrm{~cm}^{2}$ surface area) that were tested at a constant flow rate of $70 \mathrm{ml} / \mathrm{min}$, are shown in Figure 3. The relative radon reminder in the water was determined at different times of aeration. It can be seen from curve (a) in Figure 3 that only one minute of aeration is sufficient to reach to a relative Rn222 reminder of $48 \%$ from the total amount of Rn-222 present in $50 \mathrm{ml}$ of water volume which was aerated at a constant air flow rate of $70 \mathrm{ml} / \mathrm{min}$. Allowing more aeration time up to 3 minutes, rapidly removes Rn-222 from water until the relative radon reminder reaches $14 \%$ of the original amount present. With more aeration time, the elimination of Rn-222 from water is slow in responding to air bubbles, as it takes 10 minutes to reach to a relative radon reminder of less than 1\%. Curve (b) in Figure 3 shows the results from a $100 \mathrm{ml}$ water volume which was aerated at a constant air flow rate of $70 \mathrm{ml} / \mathrm{min}$; the relative $\mathrm{Rn}-222$ reminder is $84 \%$ of the total $\mathrm{Rn}-222$ present. This was achieved by aerating the water for one minute. The relative $\mathrm{Rn}-222$ reminder in three minutes aeration time is $20 \%$. After 10 minutes the relative Rn-222 reminder is only $3 \%$. Thus it seems that three minutes duration is the optimum aeration time needed to remove most of the Rn-222 present in both $50 \mathrm{ml}$ and $100 \mathrm{ml}$ water volumes.

The effect of aeration time on Rn-222 removal at a constant air flow rate of $70 \mathrm{ml} / \mathrm{min}$ for the two large volumes $(200 \mathrm{ml}$ and $300 \mathrm{ml})$ that were tested is shown in curve (c and d) in Figure 3. It cannot be compared to the $50 \mathrm{ml}$ and $100 \mathrm{ml}$ water volumes due to difference in

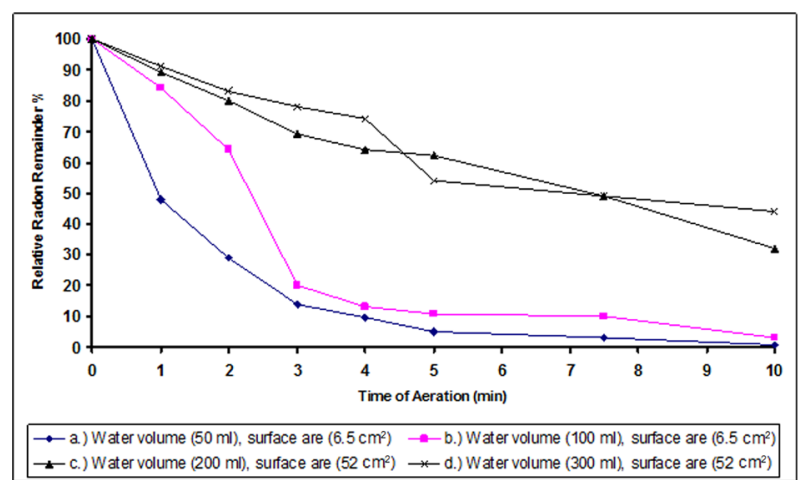

Figure 3. The effect of aeration time on $\mathbf{R n - 2 2 2}$ removal for different water volume and different surface area, using ball type diffused bubble aeration system, at a constant flow rate of $70 \mathrm{ml} / \mathrm{min}$. aerator type, although, not much Rn-222 removal was observed especially at low aeration times 1 - 5 minutes. Improving the aeration system by using a ring type aerator which produces more homogeneous bubbles distribution enhanced the Rn-222 removal from water for these large volumes. The relative radon reminder in 10 minutes aeration time is $32 \%$ for $200 \mathrm{ml}$ water volume, and $44 \%$ for $300 \mathrm{ml}$ water volume. These results appear to indicate that the constant $70 \mathrm{ml} / \mathrm{min}$. air flow rate is no longer sufficient to effectively remove radon from these relatively larger water volumes.

\subsection{Optimum Air Flow Rate for Rn-222 Removal from Water under Controlled Conditions}

The results of two repeated sets of experiments to determine the effect of air flow rate on Rn-222 removal from the four tested volumes are shown in Figure 4.

The curve (a) in Figure 4 describes the case for the 50 $\mathrm{ml}$ water volume which was aerated for $1.5 \mathrm{~min}$. The curve appears to have three sections; the first section with the largest slope represents a rapid Rn-222 removal region at $70 \mathrm{ml} / \mathrm{min}$ air flow rate. At this rate, the relative Rn-222 reminder was $49 \%$ of the total Rn-222 content.

The second section represents a slower Rn-222 removal, as it is necessary to increase the air flow rates from (242 $\mathrm{ml} / \mathrm{min}$ to $300 \mathrm{ml} / \mathrm{min}$ ) in order to decrease the relative radon reminder by $4 \%$ only.

The curve (b) in Figure 4 describes the case for 100 $\mathrm{ml}$ water volume. It is clear from the curve that the effect of air flow rate becomes weaker because the volume is doubled, yet the three stages in Rn-222 removal can still be seen. In this case, the $70 \mathrm{ml} / \mathrm{min}$. flow rate results in a relative radon remainder of $64 \%$.

The results for the two larger water volumes of $200 \mathrm{ml}$ and $300 \mathrm{ml}$ are presented in curves (c) and (d) in Figure 4. These volumes are not compared with the $50 \mathrm{ml}$ and

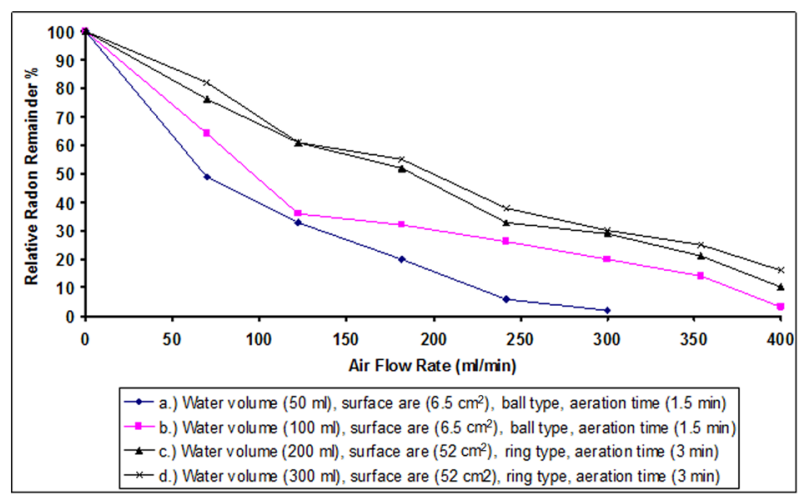

Figure 4. The effect of air flow rate on Rn-222 removal for different water volume and different surface area, using both ball and ring types diffused bubble aeration system, at a constant aeration time of $1.5 \mathrm{~min}$ (ball) and $3 \mathrm{~min}$ (ring). 
$100 \mathrm{ml}$ water volumes because there is a difference in the aerator type. Although, it can be seen that the larger volumes have a very low response to small air flow rates, at air flow rates higher than $300 \mathrm{ml} / \mathrm{min}$, low relative radon remainder was observed. The different stages in Rn-222 removal are not clearly observed in these curves, perhaps due to the fact that the air flow rates and aeration time are not large enough to cause rapid changes in fractions removed.

The optimum air flow rates required to reach a relative $\mathrm{Rn}-222$ remainder of $6 \%$ from the Rn-222 present in water is $242 \mathrm{ml} / \mathrm{min}$. for a $50 \mathrm{ml}$ water volume at an aeration time duration of $1.5 \mathrm{~min}$. The optimum value of air flow rate for Rn-222 removal from water becomes a function of the degree of removal required, depending on the actual starting amount of Rn-222 in the water. For very large volumes there is an optimum removal air flow rate value i.e. the optimum air flow rate in the case of $100 \mathrm{ml}$ water volume is $345 \mathrm{ml} / \mathrm{min}$. which is required to decrease the relative radon remainder to $14 \%$.

\subsection{Relative Rn-222 Removal at Different Air/Water Ratios Using Diffused Bubble Aeration Method}

Figure 5 represents the relative radon removal at different air/water ratios for $100 \mathrm{ml}$ water volume. It is clear from the Figure that the ratio of air/water required to remove $95 \%$ of the $\mathrm{Rn}-222$ present in the water is $6 / 1$. At the ratio $1.8 / 1$ the $\mathrm{Rn}-222$ removal percentage is $64 \%$, after this point the ratio becomes larger but with less $\mathrm{Rn}-222$ removed. A similar type of curve is shown in Figure 6. This curve shows the relative Rn-222 removal at different air/water ratios for $50 \mathrm{ml}$ water volume. The ratio of air/water required to remove $98 \%$ of the $\mathrm{Rn}-222$ present in $50 \mathrm{ml}$ water is $9 / 1$. This ratio is larger than the case for $100 \mathrm{ml}$ water volume. The reason for this is that the bubbles are more efficient in removing Rn-222 from water when they travel further to reach the water surface. The results of testing the diffused bubble aeration system appear to support the results achieved by Dixon and Lee (1991) [1], and obtained from field experiments. The shapes of the curves representing Rn-222 removal from water at different air/water ratios were similar, although different percentages of Rn-222 were removed.

These results, taken collectively, show that aeration, air flow rate and the duration of the aeration process all contribute to the efficiency of radon removal from radon rich water.

\subsection{Determination of the Natural Loss of $R \mathbf{n}-222$ on Standing for Two Surface Areas}

Surface area affects the quantity of Rn-222 released from water. The effect is shown in Figure 7. Rn-222 is ema-

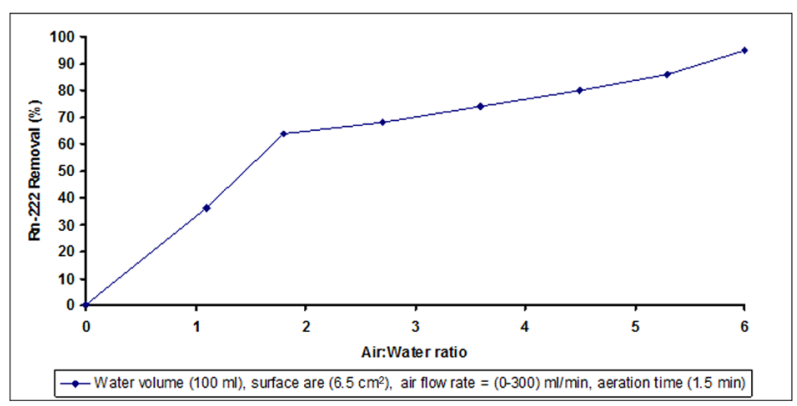

Figure 5. Rn-222 removal vs air: water ratio for $100 \mathrm{ml}$ water volume.

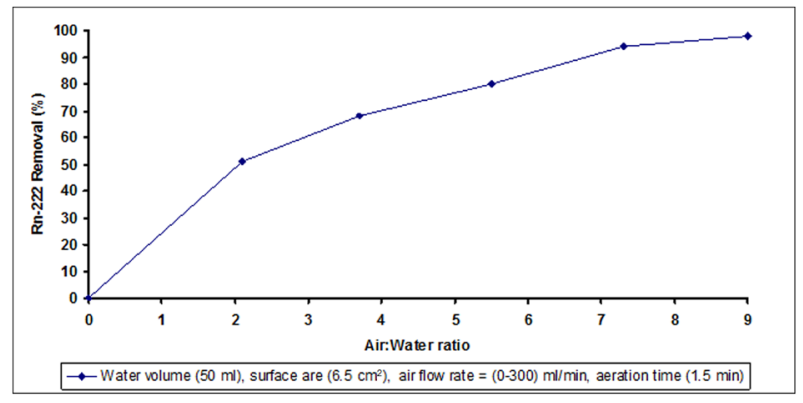

Figure 6. Rn-222 removal vs air: water ratio for $50 \mathrm{ml}$ water volume.

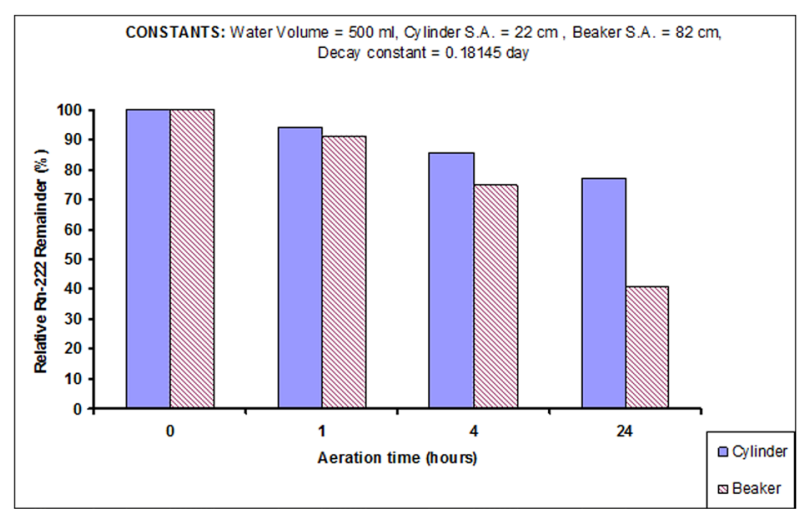

Figure 7. Natural loss of Rn-222 on standing for two surface areas.

nated from radon enriched water contained in a cylinder at a slower rate. The relative radon remainder in the cylinder is $77 \%$ after 24 hours of exposure to air, whereas the relative radon remainder measured for the same time duration in the beaker was only $41 \%$. It should be noted that these values are not corrected for Rn-222 described indicate the present of a direct relationship between the surface area of a body of water and Rn-222 loss from that water.

\section{Summary and Conclusions}

The removal of Rn-222 from artificially enriched water can be practically achieved by diffused bubble aeration 
method to greater than $98 \%$. Heat was found to have an effective ability for removing Rn-222 from water. Measured removal of Rn-222 from water that was kept at a maintained temperature of $39^{\circ} \mathrm{C}$ for 5 hours reached about $76 \%$.

For every large volume there is an optimum removal air flow rate i.e. the optimum air flow rate required to decrease the relative $\mathrm{Rn}-222$ remainder in water to about $6 \%$ is $242 \mathrm{ml} / \mathrm{min}$. for $50 \mathrm{ml}$ water volume at an aeration time of $1.5 \mathrm{~min}$. The optimum air flow rate for $100 \mathrm{ml}$ water volume is $345 \mathrm{ml} / \mathrm{min}$ which is required to decrease the relative $\mathrm{Rn}-222$ remainder to $14 \%$ in the same aeration time. The optimum aeration time for Rn-222 removal from water was found to be $3 \mathrm{~min}$. for (50 and 100) $\mathrm{ml}$ water volumes, and $10 \mathrm{~min}$. for (200 and 300) ml water volumes.

The natural loss of Rn-222 from Rn-222 rich water on standing increases with large surface area.

\section{REFERENCES}

[1] K. L. Dixon and R. G. Lee, "Occurrence of Radon in Well Supply,” Journal-American Water Works Association, Vol. 80, No. 7, 1988, pp. 65-70.

[2] E. M. Aieta, J. E. Singley, R. Trussell, K. W. Thurbjarnarson and M. J. Mc Guire, "Radionuclide in Drinking Water," Journal-American Water Works Association, Vol. 79, No. 4, 1987, pp. 144-152.

[3] C. T. Hess, J. K. Korsah and C. J. Einloth, "Radon in Houses Due to Radon in Potable Water," ACS Symposium Series, Vol. 331, No. 3, 1987, pp. 30-41. http://dx.doi.org/10.1021/bk-1987-0331.ch003

[4] M. Jacqueline, "Relationship of Radium and Radon with Geological Formations,” Lewis Publishers, Inc., Chelsea, 1990, pp. 83-90.

[5] D. P. Loomis, "The Relationship between Water-System Size and Rn-222 Concentration in North Carolina Public Water Supplies,” Health Physics, Vol. 52, No. 1, 1987, pp. 69-71.

[6] NCRP, "Calculated Long Cancer Risk to Individuals from Radon Daughter Exposure,” Report No. 78, 1984, p. 149.

[7] F. F. Cross, N. H. Harley and W. Holemann "Health Effects and Risk from Rn-222 in Drinking Water," Health Physics, Vol. 48, No. 5, 1985, pp. 649-670. http://dx.doi.org/10.1097/00004032-198505000-00006

[8] D. J. Crawford-Brown, “Analysis of the Health Risk from
Ingested Radon,” Lewis Publishers, Inc., 1990, pp. 17-25.

[9] N. E. Kinner, P. A. Quern, G. S. Schell, C. E. Lessard and J. A. Clement, "Treatment Technology for Removing Rn222 from Small Community Water Supplies,” Lewis Publishers, Inc., Chelsea, 1990, pp. 39-52.

[10] K. L. Dixon, R. G. Lee, J. Smith and P. Zielinski, "Evaluating Aeration Technology for Radon Removal," Journal-American Water Works Association, Vol. 83, No. 4, 1991, pp. 141-148.

[11] J. D. Lowry, W. F. Brutsaert, T. McEnerney and C. Molk, "Point-of-Entry Removal of Radon from Drinking Water," Journal-American Water Works Association, Vol. 79, No. 4, 1987, pp. 162-169.

[12] D. J. Crawford-Brown, “Cancer Risk from Rn-222,” Journal-American Water Works Association, Vol. 84, No. 3, 1992, pp. 77-81.

[13] J. D. Lowry and S. B. Lowry, "Radionuclides in Drinking Water," Journal-American Water Works Association, Vol. 80, No. 7, 1988, pp. 50-64.

[14] H. M. Prichrd and T. F. Gessel, "An estimate of Population Exposures Due to Rn-222 in Public Water Supplies in the Area of Houston, Texas," Health Physics, Vol. 41, No. 4, 1981, pp. 599-606. http://dx.doi.org/10.1097/00004032-198110000-00002

[15] P. Bahman, "Rn-222 in Drinking Water; an NJDEPEERF Collaborative Study,” Health Physics, Vol. 58, No. 2, 1990, pp. 209-212.

[16] R. S. Raucher and J. A. Drago, "Estimating the Cost of Compliance with the Drinking Water Standard for Rn222,” Journal-American Water Works Association, Vol. 84, No. 3, 1992, pp. 51-65.

[17] A. I. Alabdula'aly and H. B. Maghrawy, "Radon Removal from Water Supplies by Diffused Bubble Aeration System,” Journal of Radioanalytical and Nuclear Chemistry, Vol. 241, No. 1, 1999, pp. 3-9.

http://dx.doi.org/10.1007/BF02347282

[18] L. Villalba, L. Colmenero Sujo, M. E. Montero Cabrera, A. Cano Jiménez, M. Rentería Villalobos, C. J. Delgado Mendoza, L. A. Jurado Tenorio, I. Dávila Rangel and E. F. Herrera Peraza, "Radon Concentrations in Ground and Drinking Water in the State of Chihuahua, Mexico," Journal of Environmental Radioactivity, Vol. 80, No. 2, 2005, pp. 139-151. http://dx.doi.org/10.1016/j.jenvrad.2004.08.005

[19] S. Joga, S. Harmanjit, S. Surinder and B. S. Bajwa, "Estimation of Uranium and Radon Concentration in Some Drinking Water Samples,” Radiation Measurements, Vol. 43, No. 1, 2008, pp. S523-S526. 